\title{
BOX MEDIA MODEL THROUGH THE USE OF CONTEXTUAL UNDERSTANDING TO IMPROVE STUDENT LEARNING CONCEPTS IN VOLUME BEAM
}

\section{PENGGUNAAN MEDIA KARDUS MELALUI MODEL KONTEKSTUAL UNTUK MENINGKATKAN PEMAHAMAN SISWA DALAM PEMBELAJARAN KONSEP VOLUME BALOK}

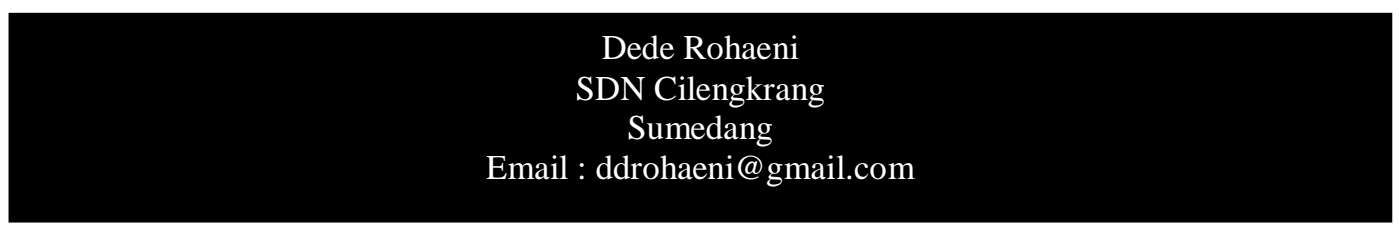

Abstract. This research is motivated Cilengkrang Elementary School fifth grade students in the learning of the beam volume is still experiencing difficulties. This happens because the learning process that takes place is conventional. Learning by applying a contextual model chosen researchers by reason students will know if the learning is associated with the real world of students. The method used in this research is a classroom action research methods to the design of the research procedure refers to the spiral model Kemmis and MC. Tujuanpenelitianini is to obtain an overview of the planning, implementation and improvement of students' understanding of the results of the application of the concept model of contextual learning in the classroom beam volume $V$ Elementary School Cilengkrang. The method used in this research is a classroom action research methods to the design of the research procedure refers to the spiral model Kemmis and MC. Taggart. Based on the implementation of the actions performed by three cycles, as a whole has shown an increase from the initial data, both process and outcomes of learning. So that the application of contextual models can enhance students' understanding of class V SDN Cilengkrang Northern District of Sumedang Sumedang district of the concept of the beam volume.

Keywords: Contextual Model, Mathematics, Mathematics Learning Objectives

Abstrak. Penelitian ini dilatarbelakangi siswa kelas V SDN Cilengkrang dalam pembelajaran volume balok masih mengalami kesulitan. Ini terjadi karena proses pembelajaran yang berlangsung bersifat konvensional. Pembelajaran dengan menerapkan model kontekstual dipilih peneliti dengan alasan siswa akan paham jika pembelajaran dikaitkan dengan dunia nyata siswa. Metode penelitian yang digunakan dalam penelitian ini adalah metode penelitian tindakan kelas dengan rancangan prosedur penelitiannya mengacu pada model spiral Kemmis dan MC. Tujuanpenelitianini yaitu untuk memperoleh gambaran mengenai perencanaan, pelaksanaan dan peningkatan hasil pemahaman siswa dengan penerapan model kontekstual dalam pembelajaran konsep volume balok di kelas V SD Negeri Cilengkrang. Metode penelitian yang digunakan dalam penelitian ini adalah metode penelitian tindakan kelas dengan rancangan prosedur penelitiannya mengacu pada model spiral Kemmis dan MC. Taggart. Berdasarkan pelaksanaan tindakan yang dilakukan sebanyak tiga siklus, secara keseluruhan telah menunjukan adanya peningkatan dari data awal, baik dalam proses maupun hasil belajar. Sehingga penerapan model kontekstual dapat meningkatkan pemahaman siswa kelas V SDN Cilengkrang Kecamatan Sumedang Utara Kabupaten Sumedang terhadap konsep volume balok.

Kata Kunci: Model Kontekstual, Matematika, Tujuan Pembelajaran Matematika

49 Penggunaan Media Kardus Melalui Model Kontekstual Untuk Meningkatkan Pemahaman Siswa Dalam Pembelajaran Konsep Volume Balok 


\section{A. PENDAHULUAN}

Pendidikan merupakan upaya sadar yang dilakukan agar siswa dapat mencapai tujuan tertentu. Jenjang pendidikan yang harus ditempuh siswa dimulai dari pendidikan dasar yakni Sekolah Dasar (SD)/Madrasah Ibtidaiyah (MI).

Matematika merupakan salah satu mata pelajaran yang dipelajari di jenjang sekolah dasar. Tujuan pembelajaran matematika menurut Kurikulum Tingkat Satuan Pendidikan tahun 2006 untuk siswa sekolah dasar (BSNP, 2006: 30) sebagai berikut:

1. Memahami konsep matematika, menjelaskan keterkaitan konsep dan mengaplikasi konsep atau alogaritma, secara luwes, akurat, efisien dan tepat dalam pemecahan masalah.

2. Menggunakan penalaran pada pola dan sifat, melakukan manipulasi matematika dengan membuat generalisasi, menyusun bukti atau menjelaskan matematika.

3. Memecahkan masalah yang meliputi kemampuan memahami masalah, merancang model matematika, menyelesaikan model dan menafsirkan solusi yang diperoleh.
4. Mengomunikasikan gagasan dengan simbol, tabel, diagram, atau media lain untuk memperjelas keadaan atau masalah.

5. Memiliki sikap menghargai kegunaan matematika dalam kehidupan yaitu memiliki rasa ingin tahu, perhatian, minat dalam mempelajari matematika, serta sikap ulet dan percaya diri dalam pemecahan masalah.

Melihat tujuan di atas, maka pembelajaran matematika harus dikemas sedemikian rupa agar tujuannya dapat tercapai. Dalam pembelajaran matematika banyak terdapat simbol-simbol yang abstrak bagi siswa. Keabstrakan objek-objek matematika perlu diupayakan agar dapat diwujudkan secara lebih konkret.

Pada kenyataannya masih banyak siswa yang pemahamannya dalam pelajaran matematika masih sangat rendah seperti di kelas V SD Negeri Cilengkrang, pemahaman siswa terhadap materi pelajaran matematika sangat rendah terutama pada materi volume balok..

Pemaparan di atas mengindikasikan akan perlunya sebuah inovasi terhadap pembelajaran yang mampu memberikan tantangan 
Edutech, Tahun 15, Vol.15, No.1, Februari 2016

tersendiri bagi siswa sebagai bentuk adanya motivasi terhadap pembelajaran matematika. Problematika tersebut bermuara pada keterbiasaan yang dialami siswa tiap kali berada dalam pembelajaran matematika.Siswa mendapat cara ajar yang sama, metode yang sama, perlakuan yang sama dan soal-soal dengantipe yang sama, walaupun konsep matematika yang diterimanya berbeda.

Berdasarkanuraian di atas, peneliti merasa tertarik untuk melakukan sebuah penelitian tindakan kelas yang dirumuskan kedalam judul "Penggunaan Media Kardus melalui model kontekstual untuk meningkatkan pemahaman siswa dalam pembelajaran konsep volume balok (penelitian tindakan kelas pada siswa kelas V SDN Cilengkrang I KecamatanSumedang Utara KabupatenSumedang)".

Berdasarkan latar belakang yang telah dipaparkan di atas, maka masalah yang muncul dalam penelitian ini dirumuskan sebagai berikut.

1. Bagaimana

perencanaan penggunaan media kardusmelalui model kontekstual dalam pembelajaran konsep volume balok?
2. Bagaimana pelaksanaan penggunaan media kardusmelalui model kontekstual?

3. Bagaimana peningkatan pemahaman siswa dalam pembelajaran konsep volume balok denganmenggunakan media kardus melalui model kontekstual?

Adapun tujuan penelitian ini adalah sebagai berikut.

1. Untuk memperoleh informasi tentang perencanaan penggunaan media kardusmelalui model kontekstual dalam pembelajaran konsep volume balok pada siswa kelas V SDN Cilengkrang Kabupaten Sumedang.

2. Untuk memperoleh informasi tentang pelaksanaan penggunaan media kardusmelalui model kontekstual dalam pembelajaran konsep volume balok pada siswa kelas V SDN Cilengkrang Kabupaten Sumedang.

3. Untuk memperoleh informasi mengenai peningkatan pemahaman siswa dalam pembelajaran konsep volume balok dengan menggunakan media kardusmelaluimodel kontekstual pada siswa kelas $\mathrm{V}$ SDN 
Cilengkrang

Sumedang.

\section{B. HASIL DAN PEMBAHASAN}

1. Metode Penelitian

Metode yang tepat dan relevan dengan masalah yang dihadapi adalah melalui metode penelitian tindakan kelas ( classroom action research ).Desain PTK yang digunakan adalah desain Kemmis \& McTaggart. Desain Kemmis \& McTaggart menggunakan system spiral refleksi yang dimulai dengan rencana, tindakan, pengamatan, refleksi, dan perencanaan kembali.

Data penelitian ini diambil dari penyusunan rancangan pelaksanaan pembelajaran (RPP), pelaksanaan pengajaran, dan penilaian hasil belajar yang dilaksanakan oleh guru kelas V di SD Negeri Cilengkrang Kabupaten Sumedang. Prosedur penelitian yang ditempuh disesuaikan dengan PTK desain Kemmis dan Mc.Taggart model spiral yang terdiridari: rencana tindakan, pelaksanaan tindakan, observasi, dan refleksi.

Instrumen yang digunakan pada penelitian ini adalah pedoman observasi, pedoman wawancara, catatan lapangan, jurnal dan lembar tes hasil belajar siswa. Teknik pengolahan data proses diperoleh dari pelaksanaan tindakan yang diperlukan untuk mengetahui gambaran penerapan model kontekstual yang berupa deskripsi proses pembelajaran dalam menentukan volume balok dengan menggunakan format observasi terhadap kinerja guru, aktivitas siswa, catatan lapangan dan wawancara. Pengolahan data hasil diperoleh dari jawaban siswa dalam tes tulis yang diberikan guru.

Analisis data pada penelitian ini dimulai dengan menelaah seluruh data yang tersedia dari berbagai sumber yang terkumpul yaitu dari hasil observasi kinerja guru dan aktivitas siswa ketika pembelajaran, catatan lapangan, tes akhir serta wawancara terhadap observer dan siswa yang dijadikan subjek penelitian. (Moleong, 2002:103) mengemukakan bahwa "analisis data adalah proses mengorganisasikan dan mengurutkan data ke dalam pola, kategori, dan satuan uraian dasar sehingga dapat ditemukan tema dan dapat dirumuskan hipotesis kerja seperti yang disarankan oleh data".

Adapun validasi data yang digunakan yaitu menurut Hopkins (Wiriaatmadja, 2005) ada beberapa bentuk validasi yang digunakan untuk 
Edutech, Tahun 15, Vol.15, No.1, Februari 2016

menguji derajat kepercayaan atau mengalami peningkatan yaitu guru derajat kebenaran penelitian tindakan melaksanakan 90\%, pada tahap kelasyaitu: (1) member chek, (2) pelaksanaan pun meningkatmenjadi triangulasi, (3) audit trail, (4) expert 83,3\%. Padasiklus III kinerja guru opinion, dan (5) key respondents menunjukkan peningkatan yaitu guru review.

telah melaksanakan $100 \%$ yang diharapkan.

\section{Hasil Penelitian}

Pelaksanaan penelitian pada b. Aktivitas Siswa dalam Penerapan penerapan model kontekstual untuk meningkatkan pemahaman siswa dalam Model Kontekstual

Berdasarkan hasil observasi siswa pembelajarankonsep volume balok pada siswa kelas V SD Negeri Cilengkrang Kabupaten Sumedang, memberikansuatu pengaruh positif terhadap proses pembelajaran yang dapat dilihat dari kinerja guru yang meliputi perencanaan, pelaksanaan dan evaluasi, aktivitas dan hasil belajar siswa yang mengalami peningkatan dari setiap siklusnya.

a. Kinerja Guru dalam Penerapan Model Kontekstual

Dari keseluruhan kinerja guru yang telah dipaparkan ternyata pada siklus I secara keseluruhan guru melaksanakan $85 \%$ indicator akan tetapi pada tahap pada siklus I Secara keseluruhan $48,4 \%$ siswa atau 15 orang siswa berada pada kategori baik dan 51,6\% siswa atau 16 orang siswa berada pada kategori cukup.

Padasiklus aktivitassiswamengalamipeningkatan, Secarakeseluruhan, $67,7 \%$ siswaatau 21 orang masuk kedalam kategori baik dan $32,3 \%$ siswa atau 10 orang masuk kedalam kategori cukup.

Padasiklus III aktivitas siswa mengalami peningkatan dari siklus II, Secara keseluruhan, $87 \%$ siswa atau 27 orang masuk kedalam kategori baik dan $13 \%$ siswa atau 4 orang berada pada kategori cukup.

pelaksanaannya baru mencapai $75 \%$.

Sehingga perlu dalam pelaksanaan

c. Hasil Belajar Siswa dengan untuk siklus berikutnya. Pada siklus II Penerapan Model Kontekstual kinerja guru secara keseluruhan 
Penerapan model kontekstual atau52\%, dengan rata-rata nilai yang telah memberikan dampak yang positif diperoleh 53. Perolehan hasil tes pada terhadap peningkatan pemahaman dan siklus II menunjukkan peningkatan hasil belajar siswa dalam konsep yaitu siwa yang tuntas belajar sebanyak volume balok di kelas V SD Negeri 22 atau 70\% dan tidak tuntas $30 \%$ Cilengkrang. Pada data awal hasil atau 9 orang siswa, rata-rata nilai yang $\begin{array}{llll}\text { belajar siswa menggambarkan dari diperoleh } & 70 .\end{array}$ jumlah siswa hanya $3 \%$ yang tuntas Perolehanhasiltespadasiklus III belajar dan $97 \%$ mendapat nilai di menunjukkan peningkatan yaitu siwa bawah nilai KKM yaitu 67. Setelah yang tuntas belajar sebanyak 27atau dilakukan tindakan hasil tes yang $87 \%$ dengan rata-rata nilai yang diperoleh pada siklus I diperoleh 79,5. Dengan demikian target menggambarkan bahwa siswa yang hasil belajar sudah tercapai. tuntas belajar sebanyak 13 orang atau Peningkatan hasil belajar siswa dapat $42 \%$ siswa dan siswa yang belum dilihat pada gambar 4.3 dan 4.4 berikut tuntas belajar sebanyak 18 orang ini.

Tabel 1.1

Hasil Tes Pemahaman Siswa Siklus I

\begin{tabular}{|c|c|c|c|c|c|c|c|c|c|c|}
\hline \multirow[b]{2}{*}{$\begin{array}{c}\text { No } \\
\text {. }\end{array}$} & \multirow[b]{2}{*}{$\begin{array}{l}\text { Nama } \\
\text { Siswa }\end{array}$} & \multicolumn{5}{|c|}{ Item Soal } & \multirow[b]{2}{*}{$\begin{array}{c}\text { Jumlah } \\
\text { Skor }\end{array}$} & \multirow[b]{2}{*}{ Nilai } & \multicolumn{2}{|c|}{ Interpretasi } \\
\hline & & 1 & 2 & 3 & 4 & 5 & & & Tuntas & $\begin{array}{l}\text { Tidak } \\
\text { Tuntas }\end{array}$ \\
\hline 1 & $\begin{array}{l}\text { Agis S B } \\
\text { L }\end{array}$ & 5 & 2 & 5 & 17 & 13 & 42 & 87,5 & $\sqrt{ }$ & \\
\hline 2 & Alfia N F & 5 & 2 & 5 & 0 & 0 & 12 & 25 & & $\sqrt{ }$ \\
\hline 3 & Acep B E & 5 & 2 & 3 & 10 & 2 & 22 & 46 & & $\sqrt{ }$ \\
\hline 4 & Cepy C & 5 & 2 & 5 & 19 & 14 & 45 & 93,8 & $\sqrt{ }$ & \\
\hline 5 & Faqih C & 5 & 2 & 5 & 1 & 0 & 13 & 27,1 & & $\sqrt{ }$ \\
\hline 6 & Fikri N & 5 & 2 & 5 & 5 & 1 & 18 & 37,5 & & $\sqrt{ }$ \\
\hline 7 & Firdaus R & 5 & 2 & 5 & 15 & 0 & 27 & 56,2 & & $\sqrt{ }$ \\
\hline 8 & Iqbal I A & 5 & 2 & 5 & 5 & 5 & 33 & 68,7 & $\sqrt{ }$ & \\
\hline 9 & Irvan F & 5 & 2 & 5 & 15 & 6 & 33 & 68,7 & $\sqrt{ }$ & \\
\hline 10 & $\begin{array}{l}\text { Yanwar } \\
\text { M G }\end{array}$ & 5 & 2 & 3 & 1 & 1 & 12 & 25 & & $\sqrt{ }$ \\
\hline 11 & $\begin{array}{l}\text { M. Rafly } \\
\text { W }\end{array}$ & 5 & 2 & 5 & 0 & 0 & 12 & 25 & & $\sqrt{ }$ \\
\hline 12 & M. Irfandi & 4 & 2 & 4 & 14 & 10 & 34 & 70,8 & $\sqrt{ }$ & \\
\hline 13 & Novianti I & 5 & 2 & 5 & 9 & 13 & 34 & 70,8 & $\sqrt{ }$ & \\
\hline
\end{tabular}

54 Penggunaan Media Kardus Melalui Model Kontekstual Untuk Meningkatkan Pemahaman Siswa Dalam Pembelajaran Konsep Volume Balok 


\begin{tabular}{|c|c|c|c|c|c|c|c|c|c|c|}
\hline 14 & $\begin{array}{l}\text { Okfhita P } \\
\text { R }\end{array}$ & 5 & 2 & 3 & 5 & 5 & 21 & 43,8 & & $\sqrt{ }$ \\
\hline 15 & Fuzza L & 1 & 2 & 5 & 12 & 4 & 24 & 50 & & $\sqrt{ }$ \\
\hline 16 & Reggy P & 5 & 2 & 5 & 12 & 6 & 30 & 68,7 & $\sqrt{ }$ & \\
\hline 17 & Rissa A & 5 & 2 & 5 & 1 & 1 & 14 & 29,1 & & $\sqrt{ }$ \\
\hline 18 & $\begin{array}{l}\text { Sandra } \mathrm{P} \\
\mathrm{A}\end{array}$ & 5 & 2 & 3 & 1 & 1 & 12 & 25 & & $\sqrt{ }$ \\
\hline 19 & Siti Z R & 5 & 2 & 5 & 0 & 0 & 12 & 25 & & $\sqrt{ }$ \\
\hline 20 & Tati K AS & 5 & 2 & 3 & 6 & 1 & 17 & 35,4 & & $\sqrt{ }$ \\
\hline 21 & Tita K AS & 5 & 2 & 3 & 17 & 12 & 41 & 85,4 & $\sqrt{ }$ & \\
\hline 22 & $\begin{array}{l}\text { Wunarlan } \\
\text { M L }\end{array}$ & 5 & 2 & 5 & 15 & 0 & 27 & 56,2 & & $\sqrt{ }$ \\
\hline 23 & $\begin{array}{l}\text { Yusman } \\
\text { M M }\end{array}$ & 5 & 2 & 5 & 17 & 10 & 37 & 77,1 & $\sqrt{ }$ & \\
\hline 24 & Yusuf P & 5 & 2 & 5 & 19 & 10 & 41 & 85,4 & $\sqrt{ }$ & \\
\hline 25 & Yadi M & 5 & 2 & 3 & 1 & 1 & 12 & 25 & & $\sqrt{ }$ \\
\hline 26 & Anisa N & 5 & 2 & 4 & 12 & 10 & 33 & 68,7 & $\sqrt{ }$ & \\
\hline 27 & Adira F P & 5 & 2 & 5 & 0 & 0 & 12 & 25 & & $\sqrt{ }$ \\
\hline 28 & $\begin{array}{l}\text { M. Hasan } \\
\text { S }\end{array}$ & 5 & 2 & 5 & 17 & 10 & 39 & 81,2 & $\sqrt{ }$ & \\
\hline 29 & Aulia H P & 5 & 2 & 3 & 8 & 3 & 21 & 43,8 & & $\sqrt{ }$ \\
\hline 30 & $\begin{array}{ll}\text { Betsy } & \text { E } \\
\text { M } & \end{array}$ & 5 & 2 & 3 & 1 & 1 & 12 & 25 & & $\sqrt{ }$ \\
\hline \multicolumn{2}{|c|}{ Jumlah } & 150 & 62 & $\begin{array}{c}13 \\
2\end{array}$ & $\begin{array}{c}27 \\
3\end{array}$ & $\begin{array}{c}15 \\
3\end{array}$ & 779 & 1643 & 12 & 18 \\
\hline \multirow{2}{*}{\multicolumn{2}{|c|}{$\begin{array}{l}\text { Rata-rata } \\
\text { Persentase }\end{array}$}} & & & & & & & 53 & & \\
\hline & & & & & & & & 53 & 42 & 58 \\
\hline
\end{tabular}

Tabel 1.2

Hasil Tes Pemahaman Siswa Siklus II

\begin{tabular}{|c|c|c|c|c|c|c|c|c|c|c|}
\hline \multirow{2}{*}{ No. } & \multirow{2}{*}{$\begin{array}{l}\text { Nama } \\
\text { Siswa } \\
\end{array}$} & \multicolumn{5}{|c|}{ Item Soal } & \multirow{2}{*}{$\begin{array}{c}\text { Jumlah } \\
\text { Skor }\end{array}$} & \multirow{2}{*}{ Nilai } & \multicolumn{2}{|c|}{ Interpretasi } \\
\hline & & 1 & 2 & 3 & 4 & 5 & & & Tuntas & TidakTuntas \\
\hline 1 & $\begin{array}{l}\text { Agis S B } \\
\mathrm{L}\end{array}$ & 5 & 2 & 5 & 19 & 14 & 45 & 93,8 & $\sqrt{ }$ & \\
\hline 2 & Alfia N F & 5 & 2 & 5 & 0 & 10 & 22 & 45,8 & & $\sqrt{ }$ \\
\hline 3 & Acep B E & 5 & 2 & 5 & 19 & 10 & 41 & 85,4 & $\sqrt{ }$ & \\
\hline 4 & Cepy C & 5 & 2 & 5 & 19 & 14 & 45 & 93,8 & $\sqrt{ }$ & \\
\hline 5 & Faqih C & 5 & 2 & 5 & 6 & 0 & 18 & 37,5 & & $\sqrt{ }$ \\
\hline 6 & Fikri N & 5 & 2 & 5 & 15 & 10 & 37 & 77,1 & $\sqrt{ }$ & \\
\hline 7 & Firdaus R & 5 & 2 & 5 & 20 & 1 & 33 & 68,8 & $\sqrt{ }$ & \\
\hline 8 & Iqbal I A & 5 & 2 & 5 & 15 & 8 & 35 & 73 & $\sqrt{ }$ & \\
\hline 9 & Irvan F & 5 & 2 & 5 & 19 & 8 & 39 & 81,2 & $\sqrt{ }$ & \\
\hline 10 & $\begin{array}{l}\text { Yanwar } \\
\text { M G }\end{array}$ & 5 & 2 & 5 & 1 & 14 & 27 & 56,2 & & $\sqrt{ }$ \\
\hline 11 & $\begin{array}{l}\text { M. Rafly } \\
\text { W }\end{array}$ & 5 & 2 & 5 & 5 & 4 & 21 & 43,8 & & $\sqrt{ }$ \\
\hline
\end{tabular}

55 Penggunaan Media Kardus Melalui Model Kontekstual Untuk Meningkatkan Pemahaman Siswa Dalam Pembelajaran Konsep Volume Balok 


\begin{tabular}{|c|c|c|c|c|c|c|c|c|c|c|}
\hline 12 & $\begin{array}{l}\text { M. } \\
\text { Irfandi }\end{array}$ & 5 & 2 & 5 & 15 & 8 & 35 & 73 & $\sqrt{ }$ & \\
\hline 13 & $\begin{array}{l}\text { Novianti } \\
\text { I }\end{array}$ & 5 & 2 & 5 & 17 & 13 & 42 & 87,5 & $\sqrt{ }$ & \\
\hline 14 & $\begin{array}{l}\text { Okfhita P } \\
\text { R }\end{array}$ & 5 & 2 & 5 & 19 & 5 & 36 & 75 & $\sqrt{ }$ & \\
\hline 15 & Fuzza L & 5 & 2 & 5 & 17 & 12 & 41 & 85,4 & $\sqrt{ }$ & \\
\hline 16 & Reggy P & 5 & 2 & 5 & 15 & 8 & 35 & 73 & $\sqrt{ }$ & \\
\hline 17 & Rissa A & 5 & 2 & 5 & 3 & 2 & 17 & 35,4 & & $\sqrt{ }$ \\
\hline 18 & $\begin{array}{l}\text { Sandra } \mathrm{P} \\
\mathrm{A}\end{array}$ & 5 & 2 & 5 & 13 & 6 & 31 & 64,6 & & $\sqrt{ }$ \\
\hline 19 & Siti Z R & 3 & 2 & 5 & 15 & 10 & 35 & 73 & $\sqrt{ }$ & \\
\hline 20 & $\begin{array}{l}\text { Tati } \quad \mathrm{K} \\
\text { AS }\end{array}$ & 5 & 2 & 5 & 15 & 0 & 27 & 56,2 & & $\sqrt{ }$ \\
\hline 21 & $\begin{array}{ll}\text { Tita } & \mathrm{K} \\
\text { AS } & \end{array}$ & 5 & 2 & 5 & 17 & 12 & 41 & 85,4 & $\sqrt{ }$ & \\
\hline 22 & $\begin{array}{l}\text { Wunarlan } \\
\text { M L }\end{array}$ & 5 & 2 & 5 & 15 & 10 & 37 & 77,1 & $\sqrt{ }$ & \\
\hline 23 & $\begin{array}{l}\text { Yusman } \\
\text { M M }\end{array}$ & 5 & 2 & 5 & 20 & 16 & 48 & 100 & $\sqrt{ }$ & \\
\hline 24 & Yusuf P & 5 & 2 & 5 & 20 & 16 & 48 & 100 & $\sqrt{ }$ & \\
\hline 25 & Yadi M & 5 & 2 & 5 & 15 & 10 & 37 & 77,1 & $\sqrt{ }$ & \\
\hline 26 & Anisa N & 5 & 2 & 5 & 19 & 14 & 45 & 93,8 & $\sqrt{ }$ & \\
\hline 27 & Adira F P & 5 & 3 & 5 & 3 & 1 & 16 & 33,3 & & $\sqrt{ }$ \\
\hline 28 & $\begin{array}{l}\text { M. Hasan } \\
\text { S }\end{array}$ & 5 & 2 & 5 & 20 & 14 & 46 & 96 & $\sqrt{ }$ & \\
\hline 29 & $\begin{array}{l}\text { Aulia } \mathrm{H} \\
\mathrm{P}\end{array}$ & 5 & 2 & 5 & 15 & 8 & 35 & 73 & $\sqrt{ }$ & \\
\hline 30 & $\begin{array}{l}\text { Betsy } E \\
M\end{array}$ & 5 & 2 & 5 & 3 & 0 & 15 & 31,2 & & $\sqrt{ }$ \\
\hline \multicolumn{2}{|c|}{ Jumlah } & 153 & 62 & 155 & 433 & 272 & 1075 & 2167 & 21 & 9 \\
\hline \multicolumn{2}{|c|}{ Rata-rata } & & & & & & & 70 & & \\
\hline \multicolumn{2}{|c|}{ Persentase } & 99 & 100 & 100 & 70 & 55 & 72,2 & 70 & 70 & 30 \\
\hline
\end{tabular}

Tabel 1.3

Hasil Tes Pemahaman Siswa Siklus III

\begin{tabular}{|c|c|c|c|c|c|c|c|c|c|c|}
\hline \multirow[b]{2}{*}{ No. } & \multirow[b]{2}{*}{ NamaSiswa } & \multicolumn{5}{|c|}{ Item Soal } & \multirow{2}{*}{$\begin{array}{c}\text { Jumlah } \\
\text { Skor }\end{array}$} & \multirow[b]{2}{*}{ Nilai } & \multicolumn{2}{|c|}{ Interpretasi } \\
\hline & & 1 & 2 & 3 & 4 & 5 & & & Tuntas & $\begin{array}{l}\text { Tidak } \\
\text { Tuntas }\end{array}$ \\
\hline 1 & Agis S B L & 5 & 2 & 5 & 19 & 14 & 45 & 93,8 & $\sqrt{ }$ & \\
\hline 2 & Alfia N F & 5 & 2 & 5 & 17 & 5 & 34 & 70,8 & $\sqrt{ }$ & \\
\hline 3 & Acep B E & 5 & 2 & 5 & 19 & 12 & 43 & 90 & $\sqrt{ }$ & \\
\hline 4 & Cepy C & 5 & 2 & 5 & 20 & 16 & 48 & 100 & $\sqrt{ }$ & \\
\hline 5 & Faqih C & 5 & 2 & 5 & 1 & 6 & 19 & 39,6 & & $\sqrt{ }$ \\
\hline 6 & Fikri N & 5 & 2 & 5 & 19 & 14 & 45 & 93,8 & $\sqrt{ }$ & \\
\hline
\end{tabular}

56 Penggunaan Media Kardus Melalui Model Kontekstual Untuk Meningkatkan Pemahaman Siswa Dalam Pembelajaran Konsep Volume Balok 


\begin{tabular}{|c|c|c|c|c|c|c|c|c|c|c|}
\hline 7 & Firdaus R & 5 & 2 & 5 & 15 & 8 & 35 & 73 & $\sqrt{ }$ & \\
\hline 8 & Iqbal I A & 5 & 2 & 5 & 15 & 10 & 37 & 77 & $\sqrt{ }$ & \\
\hline 9 & Irvan F & 5 & 2 & 5 & 19 & 14 & 43 & 90 & $\sqrt{ }$ & \\
\hline 10 & $\begin{array}{l}\text { Yanwar M } \\
\mathrm{G}\end{array}$ & 5 & 2 & 5 & 15 & 6 & 33 & 68,8 & $\sqrt{ }$ & \\
\hline 11 & $\begin{array}{l}\text { M. Rafly } \\
\text { W }\end{array}$ & 5 & 2 & 5 & 5 & 14 & 29 & 60,4 & & $\sqrt{ }$ \\
\hline 12 & M. Irfandi & 5 & 2 & 5 & 17 & 12 & 41 & 85,4 & $\sqrt{ }$ & \\
\hline 13 & Novianti I & 5 & 2 & 5 & 17 & 13 & 42 & 87,5 & $\sqrt{ }$ & \\
\hline 14 & Okfhita P R & 5 & 2 & 5 & 15 & 10 & 37 & 77 & $\sqrt{ }$ & \\
\hline 15 & Fuzza L & 5 & 2 & 5 & 17 & 12 & 41 & 85,4 & $\sqrt{ }$ & \\
\hline 16 & Reggy P & 5 & 2 & 5 & 19 & 5 & 36 & 75 & $\sqrt{ }$ & \\
\hline 17 & Rissa A & 5 & 2 & 5 & 15 & 8 & 35 & 73 & $\sqrt{ }$ & \\
\hline 18 & Sandra P A & 5 & 2 & 5 & 16 & 10 & 37 & 77 & $\sqrt{ }$ & \\
\hline 19 & Siti Z R & 5 & 2 & 5 & 20 & 8 & 40 & 83,3 & $\sqrt{ }$ & \\
\hline 20 & Tati K AS & 5 & 2 & 5 & 15 & 6 & 33 & 68,8 & $\sqrt{ }$ & \\
\hline 21 & Tita K AS & 5 & 2 & 5 & 19 & 14 & 45 & 93,5 & $\sqrt{ }$ & \\
\hline 22 & $\begin{array}{l}\text { Wunarlan } \\
\text { M L }\end{array}$ & 5 & 2 & 5 & 19 & 8 & 39 & 81,2 & $\sqrt{ }$ & \\
\hline 23 & $\begin{array}{l}\text { Yusman M } \\
\text { M }\end{array}$ & 5 & 2 & 5 & 20 & 16 & 48 & 100 & $\sqrt{ }$ & \\
\hline 24 & Yusuf P & 5 & 2 & 5 & 20 & 16 & 48 & 100 & $\sqrt{ }$ & \\
\hline 25 & Yadi M & 5 & 2 & 5 & 17 & 8 & 37 & 77,1 & $\sqrt{ }$ & \\
\hline 26 & Anisa N & 5 & 2 & 5 & 19 & 14 & 45 & 93,8 & $\sqrt{ }$ & \\
\hline 27 & Adira F P & 5 & 2 & 5 & 5 & 5 & 22 & 45,8 & & $\sqrt{ }$ \\
\hline 28 & M. Hasan S & 5 & 2 & 5 & 20 & 16 & 48 & 100 & $\sqrt{ }$ & \\
\hline 29 & Aulia H P & 5 & 2 & 5 & 19 & 4 & 35 & 73 & $\sqrt{ }$ & \\
\hline 30 & Betsy E M & 5 & 2 & 5 & 5 & 5 & 22 & 45,8 & & $\sqrt{ }$ \\
\hline \multicolumn{2}{|c|}{ Jumlah } & 155 & 62 & 155 & 497 & 323 & 1187 & 2465,6 & 26 & 4 \\
\hline \multicolumn{2}{|c|}{ Rata-rata } & & & & & & & 79,5 & & \\
\hline \multicolumn{2}{|c|}{ Persentase } & 100 & 100 & 100 & 80,2 & 65,1 & 79,8 & 79,5 & 87 & 13 \\
\hline
\end{tabular}

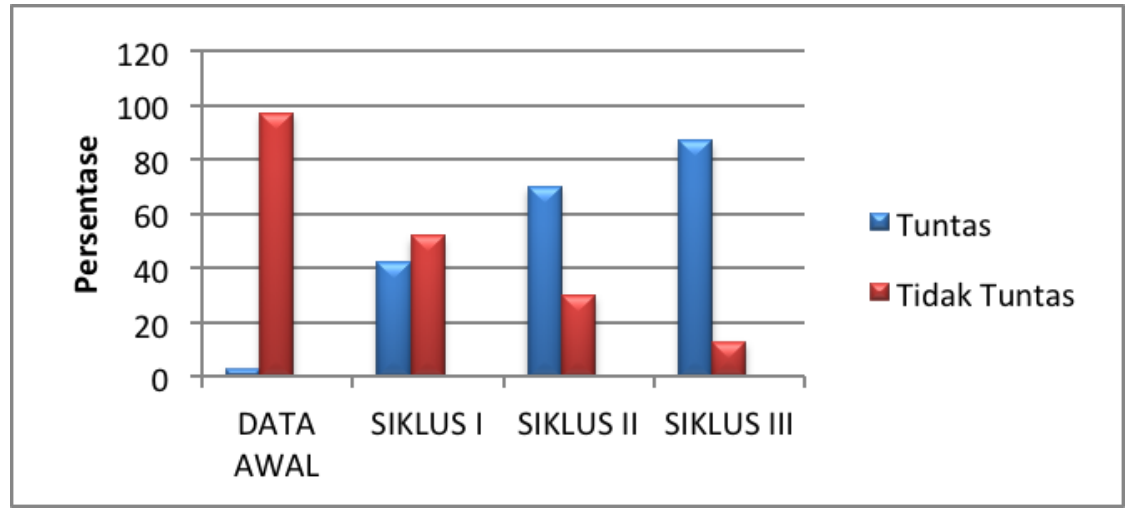

Gambar 1: Grafik Peningkatan Hasil Tes Pemahaman Siswa 
Edutech, Tahun 15, Vol.15, No.1, Februari 2016

Berdasarkan paparan di atas RPP, mempersiapkan media ternyata bahwa penggunaan media pembelajaran, mempersiapkan materi kardus melalui model kontekstual pembelajaran, mempersiapkan alat dalam pembelajaran konsep volume evaluasi dan instrumen penelitian. balok di kelas V dari setiap siklusnya Adapun ketercapaian indikator kinerja mengalami peningkatan baik dilihat guru pada perencanaan, pelaksanaan prosesnya yaitu kinerja guru dan dan evaluasi setiap siklus telah aktivitas siswa maupun hasilnya berupa nilai angka yang menjadi semakin meningkat.

\section{SIMPULAN}

Berdasarkan pada hasil penelitian dan pembahasan yang telah dipaparkan tentang pelaksanaan dan hasil tindakan dengan penerapan model kontekstual untuk meningkatkan pemahaman siswa dalam pembelajaran konsep volume balok di kelas V SDN Cilengkrang Kecamatan Sumedang UtaraKabupatenSumedang, dapat ditarik kesimpulan bahwa penggunaan media kardus melalui model kontekstual untuk meningkatkan pemahaman siswa pada materi volume balok terdiri dari tahap perencanaan, pelaksanaan, dan evaluasi.

Pada tahap perencanaan dalam penelitian ini yang melakukan kegiatan didalam tahap ini sepenuhnya dilakukan oleh guru. Kegiatan yang dilakukan meliputi mempersiapkan tercapai.

Berdasarkan gambaran yang telah peneliti paparkan di atas, telah membuktikan bahwa "jika guru melaksanakan pembelajaran dengan penggunaan media kardus melalui model pembelajaran kontekstual, maka pemahaman siswa mengenai konsep volume balok di kelas V SDN Cilengkrang Kecamatan Sumedang Utara Kabupaten Sumedang akan meningkat".

\section{DAFTAR PUSTAKA}

Arikunto, S., Suhardjono, \& Supardi (2006).Penelitian Tindakan Kelas. Jakarta: Bumi Aksara.

Asnawir, dan Basyiruddin Usman. (2002). Media Pembelajaran. Jakarta: Ciputat Pers.

Depdiknas. (2006). Kurikulum Tingkat Satuan Pendidikan (KTSP). Jakarta: BP.

Mujono, dan Suherman, A. (2007). Metode Penelitian pendidikan 
Sekolah Dasar. Bandung : UPI

PRESS.

Maulana (2008). Penelitian

Pendidikan. Bandung:

Tidakditerbitkan.

Rohani, Ahmad. (1997). Media

Instruksional Edukatif. Jakarta:

RinekaCipta.

Soenarjo, RJ. (2007). Matematika 5 SD

dan MI Kelas 5. Jakarta: Pusat

Perbukuan Departemen

Pendidikan Nasional. 